\title{
BMJ Open Course of DISease In patients reported to the Swedish CPAP Oxygen and VEntilator RegistrY (DISCOVERY) with population-based controls
}

\author{
Andreas Palm (1) , ${ }^{1,2}$ Krister Ågren, ${ }^{2}$ Ludger Grote, ${ }^{3}$ Mirjam Ljunggren, ${ }^{1}$ \\ Bengt Midgren, ${ }^{4}$ Josefin Sundh (1) , ${ }^{5} \mathrm{~J}$ Theorell-Haglöw, ${ }^{1}$ Magnus Ekström ${ }^{6}$
}

To cite: Palm A, Ågren K, Grote L, et al. Course of DISease In patients reported to the Swedish CPAP 0xygen and VEntilator RegistrY (DISCOVERY) with populationbased controls. BMJ Open 2020;10:e040396. doi:10.1136/ bmjopen-2020-040396

- Prepublication history for this paper is available online. To view these files, please visit the journal online (http://dx.doi. org/10.1136/bmjopen-2020040396).

Received 12 May 2020 Revised 10 September 2020 Accepted 11 October 2020

Check for updates

(c) Author(s) (or their employer(s)) 2020. Re-use permitted under CC BY. Published by BMJ.

For numbered affiliations see end of article.

Correspondence to Dr Andreas Palm; andreas.palm@medsci.uu.se

\section{ABSTRACT}

Purpose Chronic hypoxic and hypercapnic respiratory failure and obstructive sleep apnoea (OSA) are chronic diseases associated with decreased quality of life and increased mortality. The rationale behind the set up the retrospective nationwide DISCOVERY cohort was to study several questions including disease course and risk factors for incident disease, impaired quality of life, hospitalisation risk and mortality in patients with chronic respiratory failure with long-term oxygen therapy (LTOT), long-term mechanical ventilation (LTMV) and obstructive sleep apnoea (OSA) on treatment with continuous positive airway pressure (CPAP).

Participants and settings Data from the national quality registry for respiratory insufficiency and sleep apnoea (Swedevox) and a population-based control group from Statistics Sweden were merged with governmental registries, the Swedish Cancer Registry, the Swedish Cause of Death Registry, the Swedish Drug registry, the Swedish National Patient Registry and the Swedish Dental Health Registry and with national quality registries for diabetes, rheumatic diseases (Swedish Rheumatology Quality Registry), stroke (RiksStroke), heart failure (RiksSvikt), acute heart infarction care (SwedeHeart) and intensive care (SIR) and with socioeconomic data from Statistics Sweden (SCB).

Findings to date The cohort comprises 25804 unique patients with LTOT since 1987 (54.1\% females, age $73.3 \pm 9.8$ years, body mass index (BMI) $26.6 \pm 6.5 \mathrm{~kg} /$ $\mathrm{m}^{2}$ ), 8111 with LTMV since 1996 (48.6\% women, age $60.6 \pm 16.9$ years, BMI $\left.32.9 \pm 10.8 \mathrm{~kg} / \mathrm{m}^{2}\right), 65809$ with OSA on CPAP since 2010 (29.5\% women, age $57.2 \pm 12.5$ years, BMI $31.9 \pm 6.2 \mathrm{~kg} / \mathrm{m}^{2}$ ) and 145224 persons in a populationbased control group from same time span up to March 2018 (51.7\% women, age $49.9 \pm 20.4$ year, BMl $24.9 \pm 4.0$ years).

Future plans In patients with chronic respiratory failure and sleep apnoea important questions regarding comorbidity burden, hospitalisation rate, mortality and treatment outcomes are still unexplored to a large extent. The DISCOVERY cohort will provide unique opportunities by its size and comprehensiveness to fill this clinically relevant gap of knowledge.
Strengths and limitations of this study

- This nationwide population-based cohort is unique internationally due to its size, its high nationwide coverage, high degree of data completeness and high validity of data.

- No patients are lost to follow-up due to crosslinkage with mandatory national registries.

- To assure a high level of completeness in the Swedevox registry, the number of requested variables to be reported into the Swedevox registry has been deliberately limited, and the data thus become less detailed.

- Difficulties adjusting for confounders is a limitation in all registry-based studies.

- This is counterbalanced, at least in part, by the size of the cohort and by cross-linkage with other registries.

\section{INTRODUCTION}

Chronic hypoxic and hypercapnic respiratory failure and obstructive sleep apnoea (OSA) are associated with decreased quality of life and increased mortality. ${ }^{1-7}$ Chronic hypoxic failure is caused by pulmonary diseases such as chronic obstructive pulmonary disease (COPD) and idiopathic pulmonary fibrosis ${ }^{8}$ and can be treated with long-term oxygen therapy (LTOT). ${ }^{9}$ Chronic hypercapnic respiratory failure caused by hypoventilation is treated with long-term mechanical ventilation (LTMV). ${ }^{10}$ OSA is a highly prevalent disease of variable aetiology and continuous positive airway pressure (CPAP) ${ }^{11}$ is the firstline treatment in moderate-to-severe OSA. Large-scale outcome data are sparse in these patient groups with chronic diseases characterised by substantial respiratory distress. Despite high prevalence and substantial heathcare utilisation, several important questions on long-term treatment outcomes are not yet sufficiently studied. 
In chronic hypoxic respiratory failure, two-thirds of the patients die of cardiovascular disease (CVD) and cancer. $^{12}{ }^{13}$ There are only a few studies focusing on the effect of medications on hospitalisation and mortality in patients with respiratory failure due to diseases other than COPD. ${ }^{14}$ Furthermore, newly published data from randomised studies show that LTMV in selected patients with COPD and respiratory failure can increase survival and reduce risk for hospitalisation, ${ }^{15}$ but data from 'real-world' patient cohorts are scarce. Morbidity and mortality are very high in patients with chronic respiratory failure. ${ }^{16-18}$ However, it is insufficiently explored how socioeconomic factors such as level of education, living conditions, marital status and national origin may impact treatment decisions, adherence to treatment and overall prognosis in this large patient group. Patients with obesity hypoventilation syndrome (OHS) have an increased usage of healthcare resources compared with controls ${ }^{19}$ and initiation of LTMV on small OHS cohorts has been associated with reduced healthcare utilisation. ${ }^{20}$ However, larger population-based studies on healthcare utilisation of patients with OHS on LTMV are needed.

In OSA, several pertinent questions are still unresolved. Observational studies have shown that treatment with CPAP is associated with increased survival. ${ }^{221}$ Randomised trials were not able to consistently show any secondary prevention effects of CPAP on cardiovascular events. ${ }^{22-24}$ Furthermore, it is yet unknown how day-time sleepiness in OSA may affect the risk of incident cardiovascular disease. A higher incidence of hypertension has been observed in sleepy patients with OSA compared with patients without day-time sleepiness. ${ }^{25}$ One well-cited study on a small sample size $(n=441)$ of patients with the COPD-OSA overlap syndrome showed increased mortality and risk for hospitalisation for patients with COPD with untreated OSA compared with COPD alone. ${ }^{26}$ These results need to be verified in larger clinical-based studies.

The European Sleep Apnoea database (ESADA) study reported an increased cancer prevalence in women with OSA but not in men, but the reported cancer prevalence was low and no subanalysis for cancer subtypes was performed. ${ }^{27}$ Therefore, adequately powered large-scale studies of the possible association between OSA, gender and cancer are warranted.

Sweden offers extensive possibilities for populationbased outcome studies. There are 107 national quality registries containing individualised data concerning specific diseases or medical interventions set up to monitor and to improve the quality of healthcare. The Swedish National Board of Health and Welfare (Socialstyrelsen) manages a series of registries relating to healthcare and social services. The Swedish system of personal identity numbers (PIN $)^{28}$ allows identification of individuals in any national registry and cross-linkage between registries for longitudinal follow-up.

DISCOVERY is an acronym for Course of DISease in patients reported to the Swedish CPAP Oxygen and VEntilator RegistrY. In patients with chronic respiratory failure on LTOT and LTMV and with sleep apnoea on CPAP, important questions regarding comorbidity burden, hospitalisation rate, mortality and treatment outcomes are still unexplored to a large extent. The DISCOVERY cohort will provide unique opportunities by its size and comprehensiveness to fill this clinically relevant gap of knowledge.

\section{Cohort description}

The DISCOVERY cohort is a nation-wide populationbased cohort, including patients in the Swedevox National Quality Registry for respiratory failure, with respiratory failure starting LTOT ( $\mathrm{n}=25$ 797), LTMV (both invasive and non-invasive ventilation, $\mathrm{n}=8111$ ), patients with OSA starting CPAP ( $\mathrm{n}=65$ 803) and a population-based control cohort ( $\mathrm{n}=145224)$.

National quality registry for respiratory failure (Swedevox) Patients with LTOT and LTMV have been included prospectively in the Swedevox registry since 1 January 1987 and 1 January 1996, respectively, with $100 \%$ geographical coverage and a population-based coverage of approximately $85 \%-90 \%,{ }^{29-31}$ even though temporary geographical gaps occasionally exist. The number of centres across Sweden reporting to the LTOT arm is 48 and the number reporting to the LTMV arm is 40 . An increasing number of centres have prospectively included patients with OSA on CPAP therapy in the registry's CPAP arm prospectively since inclusion started in 1 July 2010. The geographical coverage is estimated at $80 \%$ and the number of reporting centres across Sweden is 37 in 2018. ${ }^{32}$ The primary and secondary diagnosis causing treatment with LTOT and/or LTMV are reported as presented in tables 1 and 2. A complete variable list for the Swedevox registry is presented in table 3 . Patients in the registry have scheduled follow-up visits after 1 year and those with LTMV also after 3 years. Follow-up frequencies are presented in table 4.

\section{The control group}

A population-based control group was identified from Statistics Sweden's Living Conditions Surveys (ULF/ SILC), which consists of a random selection of approximately 6000 people between the ages of 16 and 74 years in Sweden, made every year since 1987 . The control cohort is from the same time span as the study population. Data from the ULF/SILC regarding age, gender, length, weight, smoking, housing type, living area, civil status and year of study are collected for the study. ${ }^{33}$

\section{Compilation of the DISCOVERY data set}

Within the Swedevox registry, there were patients reported to more than one registry arm and also patients that had initiated a specific treatment more than once (493 patients on LTOT, 141 on LTMV and 456 on CPAP). In the control group, 45246 observations were from persons reported to ULF/SLIC on more than one occasion. The last registration in each arm was used in the subsequent analysis. In the control group, 1722 persons 
Table 1 Distribution of diagnosis and clusters of diagnosis in the LTOT arm of the DISCOVERY cohort ( $\mathrm{n}=25$ 797)

\begin{tabular}{|c|c|c|c|}
\hline Diagnosis $\mathrm{n}=$ & $\mathbf{N}(\%)$ & Cluster & $\mathbf{N}(\%)$ \\
\hline COPD & $15716(60.9)$ & Airway disease & $17.256(66.9)$ \\
\hline Emphysema due to $\alpha 1$-antitrypsin deficiency & $348(1.3)$ & & \\
\hline Other airway disease & $1192(4.6))$ & & \\
\hline Pulmonary fibrosis & $3627(14.1)$ & Parenchymal disease & $4522(17.5)$ \\
\hline Sarcoidosis & $215(0.8)$ & & \\
\hline Other parenchymal disease & $680(2.6)$ & & \\
\hline Primary pulmonary hypertension & $580(2.2)$ & Pulmonary vascular disease & $1280(5.0)$ \\
\hline Chronic pulmonary embolism & $480(1.9)$ & & \\
\hline Other pulmonary vascular disease & $220(0.8)$ & & \\
\hline Heart disease & $508(2.0)$ & Heart disease & $508(2.0)$ \\
\hline Thoracic deformation & $703(2.7)$ & Thoracic deformation & $703(2.7)$ \\
\hline Hypoventilation & $420(1.6)$ & Hypoventilation & $420(1.6)$ \\
\hline Pulmonary or pleural tumour & $426(1.7)$ & Pulmonary or pleural tumour & $86(1.7)$ \\
\hline Other diagnosis & $464(1.8)$ & Other diagnosis & $464(1.8)$ \\
\hline Waiting for definitive diagnosis & $356(1.4)$ & Waiting for definitive diagnosis & $356(1.4)$ \\
\hline
\end{tabular}

COPD, chronic obstructive pulmonary disease; LTOT, long-term oxygen therapy.

also reported to one of the arms in the Swedevox registry were excluded. The final DISCOVERY cohort consists of 25804 unique patients with LTOT, 8111 with LTMV, 65809 with OSA on treatment with CPAP and 145224 persons in the control group. Characteristics of the different arms in the DISCOVERY cohort are presented in table 5 .
The Swedevox registry and the control cohorts were merged on individual level with governmental registries with almost complete coverage: the Swedish Cancer Registry, the Swedish Cause of Death Registry, the Swedish Drug registry, the Swedish National Patient Registry (NPR) and the Swedish Dental Health Registry. In addition, data were merged with the national quality registries

Table 2 Distribution of diagnosis and clusters of diagnosis in the LTMV arm of the DISCOVERY cohort ( $\mathrm{n}=8111)$

\begin{tabular}{|c|c|c|c|}
\hline Diagnosis & $\mathbf{N}(\%)$ & Cluster & N (\%) \\
\hline OHS with hypoventilation due to obesity and/or OSA & $2764(34.1)$ & OHS & $2764(34.1)$ \\
\hline COPD & $1103(13.6)$ & Pulmonary disease & $1451(17.9)$ \\
\hline Other pulmonary disease & $348(4.3)$ & & \\
\hline Status postpolio & $381(4.7)$ & RTD & $980(12.1)$ \\
\hline Idiopathic scoliosis & $373(4.6)$ & & \\
\hline TBC sequelae & $226(2.8)$ & & \\
\hline ALS & $1058(13.0)$ & ALS & $1058(13.0)$ \\
\hline Dystrophia myotonica & $191(2.4)$ & Neuromuscular disease & $899(11.1)$ \\
\hline Duchenne's/ Becker's muscular dystrophia & $175(2.1)$ & & \\
\hline SMA & $67(0.8)$ & & \\
\hline Other neuropathies/ myopathies & $466(5.7)$ & & \\
\hline Spinal cord injury & $179(2.2)$ & Other diagnosis & $848(10.5)$ \\
\hline Central hypoventilation with otherwise normal neurology & $78(0.9)$ & & \\
\hline $\begin{array}{l}\text { Central hypoventilation secondary to brain injury/brain } \\
\text { disease }\end{array}$ & $163(2.0)$ & & \\
\hline Other diagnosis & $428(5.3)$ & & \\
\hline Waiting for definitive diagnosis & $111(1.4)$ & Waiting for definitive diagnosis & $111(1.4)$ \\
\hline
\end{tabular}

ALS, amyotrophic lateral sclerosis; LTMV, long-term mechanical ventilation; OHS, obesity-hypoventilation syndrome; OSA, obstructive sleep apnoea; RTD, restrictive thoracic diseases; SMA, spinal muscular atrophy. 
Table 3 Baseline variables and the variables at the 1-year and 3-year follow-up for the patients reported to Swedevox LTOT, LTMV and CPAP arms

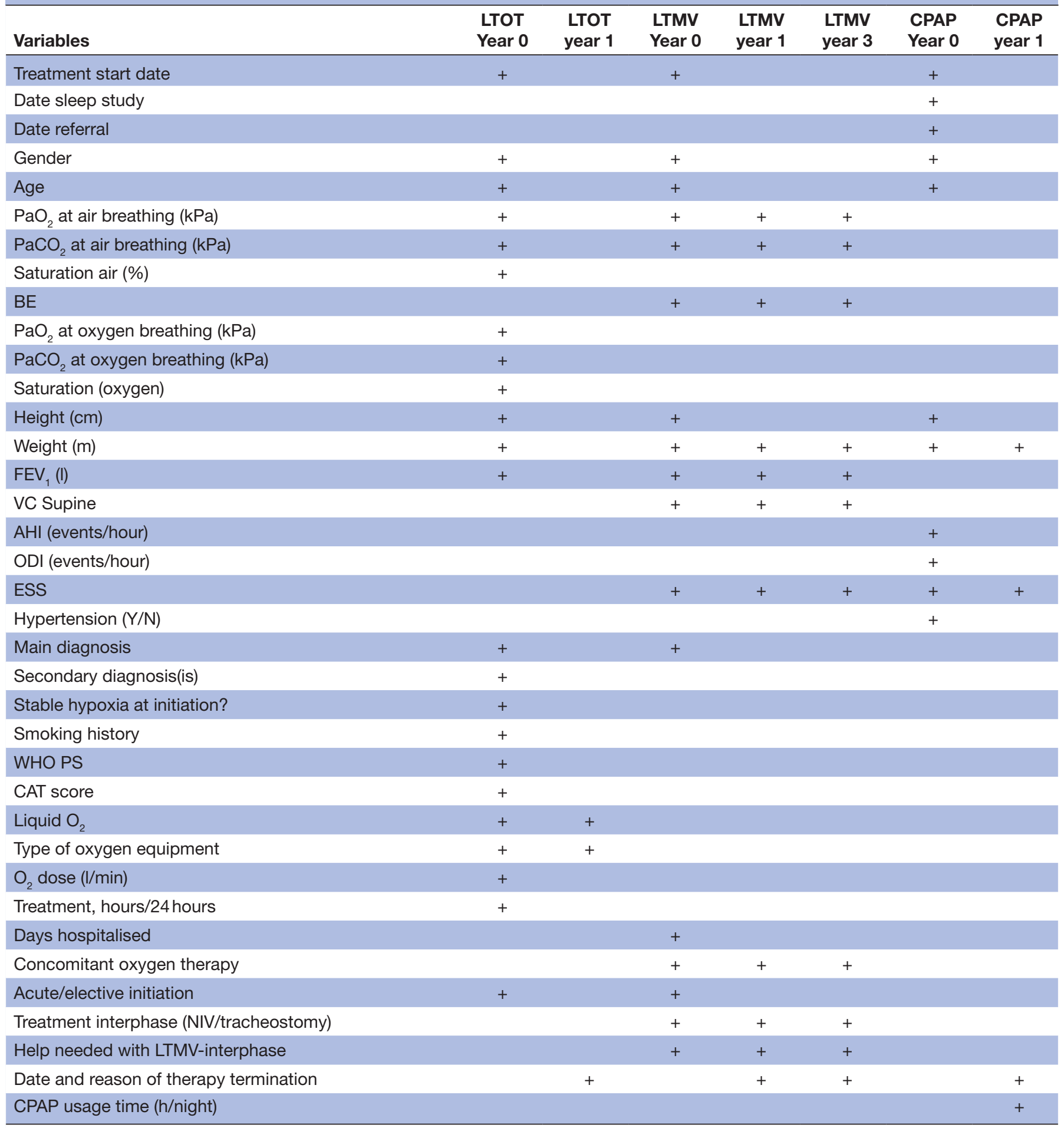

$\mathrm{AHI}$, Apnoea-Hypopnoea Index; $\mathrm{PaO}_{2}$ air, arterial blood gas tension of oxygen on air; BE, base excess; CAT, COPD assessment test; COPD, chronic obstructive pulmonary disease; CPAP, continuous positive airway pressure; ESS, Epworth Sleepiness Scale; FEV ${ }_{1}$, forced expiratory volume in $1 \mathrm{~s}$; LTMV, long-term mechanical ventilation; LTOT, long-term oxygen therapy; ODI, oxygen desaturation index; $\mathrm{PaO}_{2}$ oxygen, arterial blood gas tension of oxygen on oxygen; $\mathrm{PaCO}_{2}$, partial pressure of arterial carbon dioxide; PS, performance status; VC, vital capacity.;

for diabetes (NDR), for rheumatic diseases (Swedish Rheumatology Quality Registry (SRQ)), for stroke (RiksStroke), for heart failure (HF) (RiksSvikt), for acute heart infarction care (SwedeHeart) and for intensive care (SIR). Finally, socioeconomic data from Statistics Sweden (SCB) were added (figure 1). 
Table 4 Follow-up frequencies within the Swedevox registry for patients in the DISCOVERY cohort

\begin{tabular}{llll}
\hline & LTOT $\mathbf{n ~ ( \% )}$ & LTMV n (\%) & CPAP n (\%) \\
\hline Baseline & $25797(100 \%)$ & $8111(100 \%)$ & $65803(100 \%)$ \\
$\begin{array}{l}\text { 1-year } \\
\text { follow-up }\end{array}$ & $16015(62 \%)$ & $4624(57 \%)$ & $25854(39 \%)$ \\
$\begin{array}{l}\text { 3-year } \\
\text { follow-up }\end{array}$ & N/A & $3088(38 \%)$ & N/A \\
\hline
\end{tabular}

CPAP, continuous positive airway pressure; LTMV, long-term mechanical ventilation; LTOT, long-term oxygen therapy.

The national healthcare registries approved consignment of data. The stepwise process of cross-linkage is described in figure 2. All patients in the registries were labelled with unique serial numbers enabling merging of the different registries. The key file with personal identity numbers and serial numbers will be saved at the Swedish National Board of Health and Welfare for at least 3 years and thereby enable future corrections of errors, extraction of follow-up data and addition of other registries to the DISCOVERY cohort.

\section{Other national quality registries}

National quality registry for diabetes

The Swedish National Diabetes Registry was launched in 1996 by the Swedish Society for Diabetology for the purpose of promoting evidence-based development of diabetes care. The registry includes risk factors, diabetic complications and medications. More than $90 \%$ of all adult patients with drug-treated diabetes type 1 and 2 in Sweden are registered. ${ }^{34-36}$

\section{Swedish Rheumatology Quality Registry}

The SRQ was started in 1995 by the Swedish Rheumatology Society to improve the healthcare and treatment of patients with rheumatoid arthritis (RA), but over time it has been expanded to cover several other rheumatic diseases including ankylosing spondylitis and psoriatic arthritis, myositis, systemic lupus erythematosus and additional conditions. ${ }^{37}$ This registry contains data on pharmaceuticals, diagnoses, inpatient care, specialised outpatient care, risk factors and follow-up data. ${ }^{38}$

The coverage for patients with RA on biologic treatment is $95 \%$ and patients with ankylosing spondylitis, psoriatic arthritis and other spondyloarthropathies on biologic treatment is $86 \% .{ }^{39}$ Coverage for all patients with $\mathrm{RA}$ is estimated at $83.9 \%$ nationwide in $2017 .{ }^{40}$
National quality registry for stroke (RiksStroke)

RiksStroke was established in 1994 and has complete geographical coverage ${ }^{41}$ and a completeness of $89 \%$. It registers patients with acute stroke (acute ischaemic stroke, intracerebral haemorrhages and since 2010 also patients with transitory ischaemic attacks (TIA)) ${ }^{42}$ By 31 December 2018, 531156 patients have been included into the registry. ${ }^{43}$

\section{National quality registry for heart failure (RiksSvikt)}

Patients with HF, both in primary care and in hospitalbased care, are reported to the RiksSvikt registry. The registry was founded in 2000 and implemented throughout Sweden in $2003 .{ }^{44}$ The registry contains information on underlying diseases, diagnoses, treatment, quality of life, functional capacity, laboratory values, blood pressure, heart rate and planned follow-up. ${ }^{45}$

By 2014, 63519 unique patients have been included into the registry and there are now approximately 10000 registrations added every year. Coverage of prevalent HF in the inpatient setting is $54 \%$ but much lower in primary care. $^{46}$

National quality registry for enhancement and development of evidence-based care in heart disease (Swedeheart)

Since 1995, patients with acute coronary disease are reported to the national quality registry for acute infarction care (RIKS-HIA), a registry which since 2008 is a part of the Swedeheart registry. All coronary care units in Sweden register patients suffering from myocardial infarction and patients undergoing coronary angiography/angioplasty or heart surgery for any indication. Approximately 80000 patients are reported annually. ${ }^{47-49}$

\section{National quality registry for intensive care (SIR)}

Since 2005, Swedish intensive care units have reported patient data to Swedish Intensive Care Registry. The geographical coverage is $92 \%$. This registry contains data on diagnoses, interventions, inpatient care, patientreported outcome measures (PROM)

\section{Governmental registries administrated by the Swedish \\ National Board of Health and Welfare}

The Swedish Cancer Registry

The Swedish Cancer Registry was founded in 1958 and has an estimated completeness of $96 \%$ for all diagnosed cancers in Sweden with approximately 60000 new malignant cancer cases are reported annually. ${ }^{51}{ }^{52}$ It is mandatory for all healthcare providers to report all new cancer

Table 5 Characteristics of the DISCOVERY cohort

\begin{tabular}{lllll}
\hline & LTOT $\mathbf{n}=\mathbf{2 5} \mathbf{7 9 7}$ & LTMV $\mathbf{n = 8 1 1 1}$ & CPAP $\mathbf{n = 6 5 ~ 8 0 3}$ & Control group $\mathbf{n = 1 4 5 ~ 2 2 4}$ \\
\hline Gender $($ male \%) & $11846(45.9)$ & $4165(51.4)$ & $46375(70.5)$ & $70129(48.3)$ \\
Age (years \pm SD) & $73.3 \pm 9.8$ & $60.6 \pm 16.0$ & $57.2 \pm 12.5$ & $49.9 \pm 20.4$ \\
BMl $\left(\mathrm{kg} / \mathrm{m}^{2} \pm \mathrm{SD}\right)$ & $24.6 \pm 6.5$ & $32.9 \pm 10.8$ & $31.9 \pm 6.2$ & $24.9 \pm 4.0$ \\
\hline
\end{tabular}

BMI, body mass index; CPAP, continuous positive airway pressure; LTMV, long-term mechanical ventilation; LTOT, long-term oxygen therapy.; 


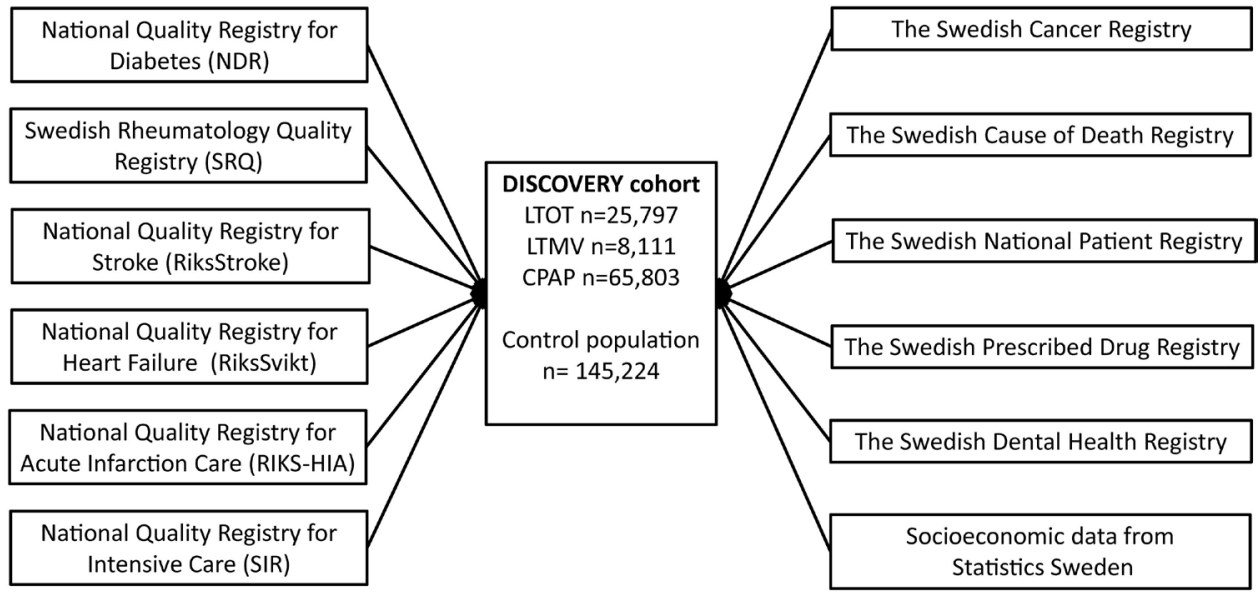

Figure 1 Sources of data for the DISCOVERY cohort. CPAP, continuous positive airway pressure; LTMV, long-term mechanical ventilation; LTOT, long-term oxygen therapy.

cases to the registries. The basis for diagnosis can be clinical examination, histology/cytology, surgery, autopsy or other examinations such as CT/MRI or laboratory investigations. Information about anatomic site and histological type and stage of the cancer, and date of diagnosis is recorded. The type of malignancy has been coded according to the Swedish versions of the International Classification of Disease system. ${ }^{53}$

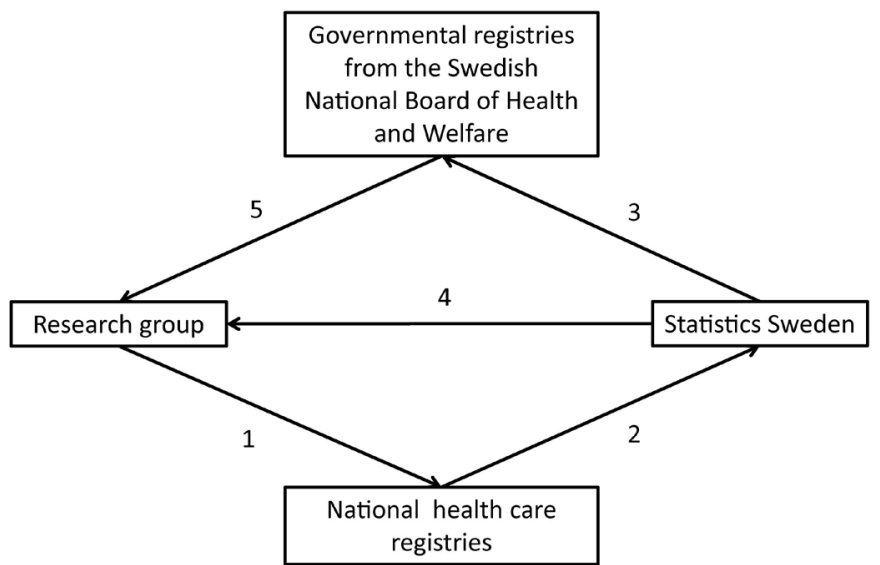

Figure 2 Flow chart for compilation of the DISCOVERY data set. The research group applied for extraction of data from the National healthcare registries (1). Data of the Swedevox population and from other national healthcare registries were sent to Statistics Sweden and a key file with personal identity numbers and unique serial numbers based on the Swedevox population was created (2). The key file and anonymised data from the other National Quality Registries were delivered to the Swedish National Board of Health and Welfare (3). Anonymised and serial number-labelled Swedevox and demographic data files and a data file of the control group file are delivered to the research group by Statistics Sweden (4). Anonymised and serial number-labelled data from the governmental and the other national quality registries were delivered to the research group by the Swedish National Board of Health and Welfare (5).
The Swedish Cause of Death Registry

Since 1952 all deaths of persons in Sweden are registered in the Swedish Cause of Death Registry. ${ }^{54}$ Up to $96 \%$ of persons included have a specific underlying cause of death recorded. ${ }^{55}$

\section{The Swedish Prescribed Drug Registry}

The Swedish Prescribed Drug Registry contains data on all dispensed prescriptions in outpatient care in Sweden since 1 July 2005. ${ }^{56}{ }^{57}$ All drugs are classified according to the Anatomical Therapeutic Chemical classification system. $^{58}$

\section{The Swedish National Patient Registry}

Data about comorbidities, hospitalisations, operations and other procedures were derived from the National Patient Registry (NPR) for inpatient and outpatient care. $^{59}$ The inpatient registry, also called Hospital Discharge Registry (NPR) was established in 1964 and has complete geographical coverage since 1987. The NPR covers nearly all somatic and psychiatric hospital admissions and as of 2001 is virtually $100 \%$ complete for data from public hospital-based outpatient care givers. The overall completeness for outpatient care is $80 \%$ due to missing data from private caregivers. Primary care is not covered in the NPR. ${ }^{60}$

\section{The Swedish Dental Health Registry}

The Swedish Dental Health Registry was initiated in 1 July 2008 and contains individual data on dental healthcare to the whole adult population of Sweden. ${ }^{61}$ The registry contains data on diagnosis, number of remaining and intact teeth, examination and treatment forms. ${ }^{62}$

\section{Demographic data from Statistics Sweden}

The Swedish Longitudinal Integrated Database for Health Insurance and Labour Market Studies (LISA) contains annual data on county and place of residence, civil status, migration, country of birth, foreign background and nationality, length of education, occupation and employment variables, incomes and allowances, sick 
Table 6 Cross-tabulation of the Swedevox registry population and control population in relation to national quality registries and mandatory governmental registries

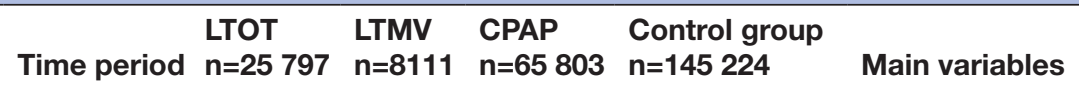

Swedish national quality registries

National quality registry 2 Jan 1997- $3002 \quad 2160 \quad 15101 \quad 13056 \quad$ Anthropometrics, biochemical analysis for diabetes $n=333194$ Apr $2019 \quad$ including HbA1c, physical activity,

unique patients smoking and snuff habits, blood pressure, complications to diabetes (retinopathy, albuminuria, foot complications).

\begin{tabular}{|c|c|c|c|c|c|c|}
\hline $\begin{array}{l}\text { Swedish Rheumatology } \\
\text { Quality Registry } n=1584 \\
\text { unique patients }\end{array}$ & $\begin{array}{l}20 \text { Aug } \\
2009-20 \text { Jan } \\
2020\end{array}$ & 99 & 46 & 630 & 809 & $\begin{array}{l}\text { Pharmaceuticals, diagnoses, inpatient care, } \\
\text { specialised outpatient care, risk factors and } \\
\text { follow-up data. }\end{array}$ \\
\hline $\begin{array}{l}\text { National quality registry } \\
\text { for stroke } n=9149 \\
\text { unique patients }\end{array}$ & $\begin{array}{l}1 \text { Jan 2001- } \\
31 \text { Dec } 2017\end{array}$ & 1057 & 412 & 2152 & 5528 & $\begin{array}{l}\text { Pharmaceuticals, risk factors (atrial } \\
\text { fibrillation, diabetes, smoking habits), length } \\
\text { of hospitalisation, details about thrombolysis } \\
\text { and medical investigation. }\end{array}$ \\
\hline $\begin{array}{l}\text { National quality registry } \\
\text { for heart failure } n=4712 \\
\text { unique patients }\end{array}$ & $\begin{array}{l}9 \text { Mar } 2002- \\
17 \text { May } 2019\end{array}$ & 1119 & 457 & 1460 & 1676 & $\begin{array}{l}\text { Anthropometrics, pharmaceuticals, } \\
\text { smoking habits, aetiology of heart failure, } \\
\text { cardiovascular comorbidities, NYHA function } \\
\text { class, ultrasonographic findings, cardiac } \\
\text { implantable electronic device therapy. }\end{array}$ \\
\hline $\begin{array}{l}\text { National quality registry } \\
\text { for acute infarction } \\
n=23164 \text { unique } \\
\text { patients }\end{array}$ & $\begin{array}{l}23 \text { Jan } \\
1991-17 \text { Dec } \\
2018\end{array}$ & 4394 & 1263 & 6470 & 11037 & $\begin{array}{l}\text { Anthropometrics, pharmaceuticals, } \\
\text { smoking and snuff habits, medical } \\
\text { history, biochemical analysis, reperfusion } \\
\text { therapy, electrical devices, stress test, } \\
\text { echocardiography, CPAP therapy, length of } \\
\text { hospitalisation. }\end{array}$ \\
\hline
\end{tabular}

\section{Swedish governmental registries}

\begin{tabular}{|c|c|c|c|c|c|c|}
\hline $\begin{array}{l}\text { National Cancer } \\
\text { Registry } n=38291 \\
\text { cancer diagnosis }\end{array}$ & $\begin{array}{l}5 \text { Jan } 1987- \\
31 \text { Dec } 2017\end{array}$ & 4984 & 1355 & 6904 & 25048 & Date and ICD number of cancer diagnosis \\
\hline $\begin{array}{l}\text { National Cause of } \\
\text { Death Registry } n=60 \\
763 \text { deaths }\end{array}$ & $\begin{array}{l}1 \text { Jan } 1996- \\
31 \text { Dec } 2018\end{array}$ & 23573 & 4970 & 2786 & 29434 & $\begin{array}{l}\text { Date of death, primary cause of death, } \\
\text { contributing cause(s) of death. }\end{array}$ \\
\hline
\end{tabular}

\section{National Patient Registry}

Inpatient registry $n=9 \quad$ 1 Jan 1987- $288024 \quad 103641 \quad 143198 \quad 417485$
52348 care events $\quad 31$ Dec 2017

\begin{tabular}{|c|c|c|c|c|c|}
\hline $\begin{array}{l}\text { Outpatient registry } n=3 \\
736276 \text { visits }\end{array}$ & $\begin{array}{l}1 \text { Jan } 2001- \\
31 \text { Dec } 2017\end{array}$ & 264873 & 1100001 & 1982901 & $\begin{array}{l}\text { Date of visit, hospital code, main diagnosis, } \\
\text { secondary diagnosis(es), surgical diagnosis. }\end{array}$ \\
\hline $\begin{array}{l}\text { National Prescribed } \\
\text { Drugs Registry } \\
\mathrm{n}=14519303 \text { drug } \\
\text { prescriptions }\end{array}$ & $\begin{array}{l}14 \text { March } 1727676 \\
2005-31 \text { Dec } \\
2018\end{array}$ & 911168 & 4650203 & 7230256 & $\begin{array}{l}\text { Prescription date, expedition date, ATC- } \\
\text { code, information about all dispensed } \\
\text { prescriptions, cost. }\end{array}$ \\
\hline $\begin{array}{l}\text { National Dental Health } \\
\text { Registry } n=2869575 \\
\text { visits }\end{array}$ & $\begin{array}{l}1 \text { Jul } 2008- \\
30 \text { Dec } 2018\end{array}$ & 51812 & 982615 & 1760684 & $\begin{array}{l}\text { Date of visit, number of intact and remaining } \\
\text { teeth. }\end{array}$ \\
\hline
\end{tabular}

Time period is 5 years prior to inclusion into the Swedevox registry until end of study period.

ATC-code, Anatomical Therapeutic Chemical code; CPAP, continuous positive airway pressure; HbA1c, glycated haemoglobin; ICD, International Classification of Disease; ICU, intensive care unit; LTMV, long-term mechanical ventilation; LTOT, long-term oxygen therapy; NYHA, New York Heart Association. 
leave and incomes. LISA covers the adult Swedish population aged $\geq 16$ years registered on 31 December each year since 1990. The completeness is estimated at $95 \% .{ }^{63}$ Data were also retrieved from Statistics Sweden on housing conditions.

Patients in the DISCOVERY cohort were continuously followed-up when being registered in other national quality registries or in the mandatory governmental registries due to death, when receiving a cancer diagnosis, when being prescribed medications, when being hospitalised, when receiving outpatient care at a public hospital and when receiving publicly financed dental care. There is generally follow-up data available until 12 March 2018. For the DISCOVERY cohort, there is longitudinal data available up to 31 December 2017 in the national cancer and the national cause of death registries and up to 31 December 2018 in the National Patient, National Prescribed Drugs and the National Dental Health registries. The frequency the study population appeared in the other registries is presented in table 6 . No patients except those who emigrate are lost to follow-up due to the crosslinking with mandatory governmental registries.

\section{Findings to date}

Several studies from the Swedevox registry have previously been published and a complete publication list can be found in the Swedevox annual report $2018 .{ }^{32}$ In patients with COPD and respiratory insufficiency, pharmacological treatment for cardiovascular diseases ${ }^{64}$ and high doses of benzodiazepines and/or opioids ${ }^{65}$ associates with increased risks for hospitalisation and mortality in contrast to patients with COPD without respiratory insufficiency. ${ }^{667}$ In interstitial lung disease, no association has been found between benzodiazepines and/or opioids and risk for mortality and hospitalisation. ${ }^{14}$ Previous studies from the LTOT arm have shown that despite improved oxygen and pharmacological treatment with bronchodilators in patients with COPD, the age-adjusted survival in patients with LTOT has not improved. ${ }^{12}$ Characteristics of patients receiving LTOT has changed markedly over time. Since the first LTOT studies ${ }^{6869}$ and since 1987, when the Swedevox registry was launched, mean age at initiation of LTOT has increased by approximately 10 years; a majority of patients receiving LTOT are women and the burden of comorbidities has increased. ${ }^{12} 3270$

The LTMV group is very inhomogeneous with differences in survival and mean age between groups as a consequence (figure 3). A previous study on Swedevox data has shown that women with OHS are older and more obese, and they have a more advanced OHS and more often initiate LTMV under non-elective conditions than men. ${ }^{17}$ Female gender and presence of hypertension were associated with non-adherence to CPAP therapy, whereas higher age, more severe OSA, BMI up to 35 and use of a humidifier were associated with adherence. ${ }^{18}$ The mortality among those with non-adherence was nearly doubled. A recently submitted study from the DISCOVERY cohort showed that civil status, educational level, household

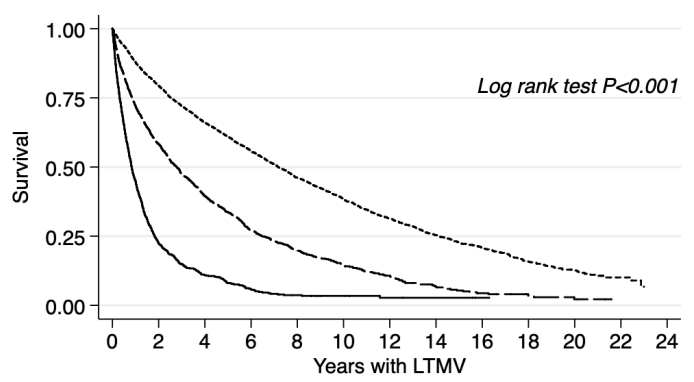

Number at risk

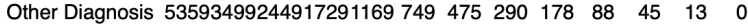

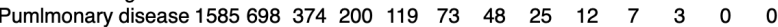

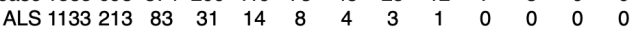

-...-- Other diagnosis (59,8 years)

- - Pulmonary disease $(67,9$ years $)$ ALS (64,2 years)

Figure 3 Kaplan-Meier estimate showing heterogenicity of survival in patients with LTMV reported to the Swedevox registry 1996-2018. Mean age for each group is stated in the legend. ALS, amyotrophic lateral sclerosis; LTMV, long-term mechanical ventilation.

income and foreign background are strong predictors for adherence to CPAP therapy in patients with OSA. ${ }^{71}$

Thus, the DISCOVERY database will be used to study factors associated with incidence, progression, worse quality of life, hospitalisation, comorbidity and mortality in patients with chronic respiratory failure with LTOT, LTMV and OSA on CPAP treatment. The detailed planning is ongoing.

\section{Strengths and limitations}

This nationwide population-based cohort is unique internationally due to its size, its high nationwide coverage and its high degree of data completeness. A recent validation study support that Swedevox data are valid, of high quality and suitable for use in research. ${ }^{72}$ No patients are lost to follow-up due to cross-linkage with mandatory national registries. Another important strength is the large population-based control group collected during the same time period as the Swedevox patients. The Swedish system with personal identity numbers enables linking of individuals in any national registry which provides the opportunity to create a unique database allowing analysis of longitudinal data from different data sources. A number of limitations need to be mentioned. To assure a high level of completeness in the Swedevox registry, the number of requested variables to be reported into the Swedevox registry has been deliberately limited, and the data thus become less detailed. This is counterbalanced, however, at least in part, by the size of the cohort. The assessment of comorbidities may be less detailed as only hospital-based diagnosis are captured in the final DISCOVERY database. However, data from drug prescription and drug utility pattern on each individual patient allow for a precise adjustment of concurrent drug treatment. It might be argued that this procedure may have the advantage of more precise control of comorbidities as we can adjust for only the more severe, drugtreated conditions. Another limitation is that the national 
quality registries are not mandatory with varying coverage as a consequence. Difficulties adjusting for confounders is a limitation in all registry-based studies.

\section{COLLABORATION}

Requests for specific research projects and collaborative work are encouraged and can be addressed to the corresponding author.

\section{Patient and public involvement}

A representative from the patient organisation 'the Swedish Heart and Lung Association' is a member of the Swedevox Registry's steering committee and has been involved in study design discussions. Results from future studies from the DISCOVERY cohort will be submitted for publication in peer-reviewed journals and presented at relevant conferences.

\section{Author affiliations}

${ }^{1}$ Department of Medical Sciences, Respiratory, Allergy and Sleep Research, Uppsala Universitet, Uppsala, Sweden

${ }^{2}$ Centre for Research and Development, Uppsala University/Region of Gävleborg, Gavle, Sweden

${ }^{3}$ Internal Medicine and Clinical Nutrition, Goteborgs Universitet, Goteborg, Sweden ${ }^{4}$ Department of Clinical Sciences, Division of Respiratory Medicine \& Allergology, Lunds University Faculty of Medicine, Lund, Sweden

${ }^{5}$ Department of Respiratory Medicine, School of Medical Sciences, Örebro University, Örebro, Sweden

${ }^{6}$ Department of Clinical Sciences, Division of Respiratory Medicine \& Allergology, Lund University, Lund, Sweden

Acknowledgements The authors would like to thank all centres in Sweden reporting data to the Swedevox registry and all patients letting themselves be reported. The authors would also like to thank the Swedish Heart and Lung Association for the commitment in the Swedevox registry's steering committee.

Contributors Project administration: AP and MPE (principal investigator). Data analysis: AP and KÅ. First manuscript draft: AP. Contribution to the study design, critical revision for important intellectual content and approval of final version to be published: AP, LG, ML, BM, JS, JT-H, MPE.

Funding The work was supported by the Swedish Society for Sleep Research and Sleep Medicine, Uppsala-Örebro Regional Research Council (Log Nos RFR-931234), Centre for Research and Development, Uppsala University/Region Gävleborg (Log Nos CFUG-925881), Bror Hjerpstedt's Foundation and the Fagerström foundation. ME was supported by unrestricted grants from the Swedish Society for Medical Research and the Swedish Research Council (Dnr 2019-02081).

Competing interests LG reports no conflicts of interest related to the submitted work but outside the submitted work: grants from Bayer, Resmed, Respironics/ Philips, Desitin, the European Respiratory Society and non-financial support from Itamar Medical and Resmed; speakers bureau for Resmed, Philips, AstraZeneca and Fisher and Paykel; patent on sleep apnoea therapy issued. No conflicts of interest are declared for any of the other authors.

Patient and public involvement Patients and/or the public were not involved in the design, or conduct, or reporting, or dissemination plans of this research.

Patient consent for publication Not required.

Provenance and peer review Not commissioned; externally peer reviewed.

Data availability statement Data are available on reasonable request. The DISCOVERY data are not freely available as they are subject to secrecy in accordance with the Swedish Public Access to Information and Secrecy Act. Data are available after approval from the Swedish Ethical Review Authority (https:// etikprovningsmyndigheten.se) for researchers who meet the criteria for access to confidential data.

Open access This is an open access article distributed in accordance with the Creative Commons Attribution 4.0 Unported (CC BY 4.0) license, which permits others to copy, redistribute, remix, transform and build upon this work for any purpose, provided the original work is properly cited, a link to the licence is given, and indication of whether changes were made. See: https://creativecommons.org/ licenses/by/4.0/.

\section{ORCID iDs}

Andreas Palm http://orcid.org/0000-0002-0590-0417

Josefin Sundh http://orcid.org/0000-0003-1926-8464

\section{REFERENCES}

1 Nowbar S, Burkart KM, Gonzales R, et al. Obesity-associated hypoventilation in hospitalized patients: prevalence, effects, and outcome. Am J Med 2004;116:1-7.

2 Marin JM, Carrizo SJ, Vicente E, et al. Long-term cardiovascular outcomes in men with obstructive sleep apnoea-hypopnoea with or without treatment with continuous positive airway pressure: an observational study. Lancet 2005;365:1046-53.

3 Gustafson T, Franklin KA, Midgren B, et al. Survival of patients with kyphoscoliosis receiving mechanical ventilation or oxygen at home. Chest 2006;130:1828-33.

4 Young T, Finn L, Peppard PE, et al. Sleep disordered breathing and mortality: eighteen-year follow-up of the Wisconsin sleep cohort. Sleep 2008;31:1071-8.

5 Punjabi NM, Caffo BS, Goodwin JL, et al. Sleep-disordered breathing and mortality: a prospective cohort study. PLOS Med 2009;6:e1000132.

6 Hardinge M, Annandale J, Bourne S, et al. British thoracic Society guidelines for home oxygen use in adults: accredited by NICE. Thorax 2015;70:11-43.

$7 \mathrm{Ng} \mathrm{L}$, Khan F, Young CA, et al. Symptomatic treatments for amyotrophic lateral sclerosis/motor neuron disease. Cochrane Database Syst Rev 2017;1:CD011776.

8 Tanash HA, Huss F, Ekström M. The risk of burn injury during long-term oxygen therapy: a 17-year longitudinal national study in Sweden. Int J Chron Obstruct Pulmon Dis 2015;10:2479-84.

9 Hardinge M, Annandale J, Bourne S, et al. British thoracic Society guidelines for home oxygen use in adults. Thorax 2015;70:11-43.

10 Simonds AK. Home mechanical ventilation: an overview. Ann Am Thorac Soc 2016;13:2035-44.

11 Sullivan CE, Issa FG, Berthon-Jones M, et al. Reversal of obstructive sleep apnoea by continuous positive airway pressure applied through the nares. Lancet 1981:1:862-5.

12 Ekström MP, Wagner P, Ström KE. Trends in cause-specific mortality in oxygen-dependent chronic obstructive pulmonary disease. $\mathrm{Am} \mathrm{J}$ Respir Crit Care Med 2011;183:1032-6.

13 Ekström M, Franklin KA, Ström KE. Increased relative mortality in women with severe oxygen-dependent COPD. Chest 2010;137:31-6.

14 Bajwah S, Davies JM, Tanash H, et al. Safety of benzodiazepines and opioids in interstitial lung disease: a national prospective study. Eur Respir J 2018;52:1801278

15 Köhnlein T, Windisch W, Köhler D, et al. Non-invasive positive pressure ventilation for the treatment of severe stable chronic obstructive pulmonary disease: a prospective, multicentre, randomised, controlled clinical trial. Lancet Respir Med 2014;2:698-705.

16 Sundh J, Ekström M. Risk factors for developing hypoxic respiratory failure in COPD. Int J Chron Obstruct Pulmon Dis 2017;12:2095-100.

17 Palm A, Midgren B, Janson C, et al. Gender differences in patients starting long-term home mechanical ventilation due to obesity hypoventilation syndrome. Respir Med 2016;110:73-8.

18 Palm A, Midgren B, Theorell-Haglöw J, et al. Factors influencing adherence to continuous positive airway pressure treatment in obstructive sleep apnea and mortality associated with treatment failure - a national registry-based cohort study. Sleep Med 2018;51:85-91.

19 Jennum P, Ibsen R, Kjellberg J. Morbidity prior to a diagnosis of sleep-disordered breathing: a controlled national study. J Clin Sleep Med 2013;9:103-8.

20 Berg G, Delaive K, Manfreda J, et al. The use of healthcare resources in obesity-hypoventilation syndrome. Chest 2001;120:377-83.

21 Campos-Rodriguez F, Martinez-Garcia MA, de la Cruz-Moron I, et al. Cardiovascular mortality in women with obstructive sleep apnea with or without continuous positive airway pressure treatment: a cohort study. Ann Intern Med 2012;156:115-22.

22 Peker Y, Glantz H, Eulenburg C, et al. Effect of positive airway pressure on cardiovascular outcomes in coronary artery disease patients with Nonsleepy obstructive sleep apnea. The 
RICCADSA randomized controlled trial. Am J Respir Crit Care Med 2016;194:613-20.

23 McEvoy RD, Antic NA, Heeley E, et al. CPAP for prevention of cardiovascular events in obstructive sleep apnea. N Engl J Med 2016;375:919-31.

24 Barbé F, Durán-Cantolla J, Sánchez-de-la-Torre M, et al. Effect of continuous positive airway pressure on the incidence of hypertension and cardiovascular events in nonsleepy patients with obstructive sleep apnea: a randomized controlled trial. JAMA 2012;307:2161-8.

25 Kapur VK, Resnick HE, Gottlieb DJ. For the sleep heart health study G sleep disordered breathing and hypertension: does self-reported sleepiness modify the association? Sleep 2008;31:1127-32.

26 Marin JM, Soriano JB, Carrizo SJ, et al. Outcomes in patients with chronic obstructive pulmonary disease and obstructive sleep apnea: the overlap syndrome. Am J Respir Crit Care Med 2010;182:325-31.

27 Pataka A, Bonsignore MR, Ryan S, et al. Cancer prevalence is increased in females with sleep apnoea: data from the ESADA study. Eur Respir J 2019;53:1900091.

28 Ludvigsson JF, Otterblad-Olausson P, Pettersson BU, et al. The Swedish personal identity number: possibilities and pitfalls in healthcare and medical research. Eur J Epidemiol 2009;24:659-67.

29 Ström K, Boe J. A national register for long-term oxygen therapy in chronic hypoxia: preliminary results. Eur Respir J 1988;1:952-8.

30 Jäger L, Franklin KA, Midgren B, et al. Increased survival with mechanical ventilation in posttuberculosis patients with the combination of respiratory failure and chest wall deformity. Chest 2008;133:156-60.

31 Emilsson L, Lindahl B, Köster M, et al. Review of 103 Swedish healthcare quality registries. $J$ Intern Med 2015;277:94-136.

32 Swedevox annual report for 2019, 2020. Available: https://www.ucr. uu.se/swedevox/rapporter/arsrapporter [Accessed 9 Nov 2020].

33 Living conditions surveys (ULF/SILC)., 2020. Available: http://www. scb.se/le0101-en [Accessed 9 Nov 2020].

34 Gudbjörnsdottir S, Cederholm J, Nilsson PM, et al. The National diabetes register in Sweden: an implementation of the St. Vincent Declaration for quality improvement in diabetes care. Diabetes Care 2003;26:1270-6.

35 Eliasson B, Gudbjörnsdottir S. Diabetes care-improvement through measurement. Diabetes Res Clin Pract 2014;106:S291-4.

36 National quality Registry for diabetes (NDR) with SWEDIABKIDS, 2020. Available: http://kvalitetsregister.se/englishpages/findaregistry/ registerarkivenglish/nationalqualityregistryfordiabetesndrwithswe diabkids.2161.html [Accessed 9 Nov 2020].

37 Eriksson JK, Askling J, Arkema EV. The Swedish rheumatology quality register: optimisation of rheumatic disease assessments using register-enriched data. Clin Exp Rheumatol 2014;32:S-147-9.

38 National quality Registry for rheumatic diseases (SRQ), 2019. Available: http://kvalitetsregister.se/englishpages/findaregistry/ registerarkivenglish/nationalqualityregistryforrheumaticdiseasessrq 2210.html [Accessed 11 Oct 2019].

39 Wadström H, Eriksson JK, Neovius M, et al. How good is the coverage and how accurate are exposure data in the Swedish biologics register (ARTIS)? Scand J Rheumatol 2015;44:22-8.

40 The Swedish rheumatology quality register, 2020. Available: http:// srq.nu [Accessed 9 Nov 2020].

41 Asplund K, Hulter Asberg K, Norrving B, et al. Riks-stroke - a Swedish national quality register for stroke care. Cerebrovasc Dis 2003:15:5-7.

42 National quality Registry for stroke (Riksstroke), 2020. Available: http://kvalitetsregister.se/englishpages/findaregistry/ registerarkivenglish/nationalqualityregistryforstrokeriksstroke.2216. html [Accessed 9 Nov 2020].

43 Swedish stroke register, RiksStroke, 2020. Available: http://www. riksstroke.org/wp-content/uploads/2019/09/Årsrapport-2018engelsk-sammanfattning.pdf [Accessed 9 Nov 2020].

44 Jonsson A, Edner M, Alehagen U, et al. Heart failure registry: a valuable tool for improving the management of patients with heart failure. Eur J Heart Fail 2010;12:25-31.

45 National quality Registry for heart failure (RiksSvikt), 2020 Available: http://kvalitetsregister.se/englishpages/findaregistry/ registerarkivenglish/nationalqualityregistryforheartfailurerikssvikt. 2169.html [Accessed 9 Nov 2020].

46 Savarese G, Vasko P, Jonsson Åsa, et al. The Swedish heart failure registry: a living, ongoing quality assurance and research in heart failure. Ups J Med Sci 2019;124:65-9.

47 Götberg M, Christiansen EH, Gudmundsdottir I, et al. Instantaneous Wave-Free ratio versus fractional flow reserve guided intervention (iFR-SWEDEHEART): rationale and design of a multicenter, prospective, registry-based randomized clinical trial. Am Heart $J$ 2015;170:945-50.
48 Jernberg T, Attebring MF, Hambraeus K, et al. The Swedish Websystem for enhancement and development of evidence-based care in heart disease evaluated according to recommended therapies (SWEDEHEART). Heart 2010;96:1617-21.

49 SwedeHeart, 2020. Available: http://kvalitetsregister.se/englishpages/ findaregistry/registerarkivenglish/nationalqualityregistryforenhanc ementanddevelopmentofevidencebasedcareinheartdiseaseswed eheart.2244.html [Accessed 9 Nov 2020]

50 National quality Registry for intensive care (Sir), 2020. Available: $\mathrm{http}: / /$ kvalitetsregister.se/englishpages/findaregistry/ registerarkivenglish/nationalqualityregistryforintensivecaresir.2175. html [Accessed 9 Nov 2020].

51 Barlow L, Westergren K, Holmberg L, et al. The completeness of the Swedish cancer register: a sample survey for year 1998. Acta Oncol 2009;48:27-33.

52 The Swedish cancer registry, 2020. Available: https://www. socialstyrelsen.se/statistik-och-data/register/alla-register/ cancerregistret/ [Accessed 9 Nov 2020].

53 Icd-10 Version:2016, 2019. Available: https://icd.who.int/browse10/ 2016/en [Accessed 11 Oct 2019].

54 The Swedish cause of death registry, 2020. Available: https:// www.socialstyrelsen.se/statistik-och-data/register/alla-register/ dodsorsaksregistret/ [Accessed 9 Nov 2020].

55 Brooke HL, Talbäck M, Hörnblad J, et al. The Swedish cause of death register. Eur J Epidemiol 2017;32:765-73.

56 Wettermark B, Hammar N, Fored CM, et al. The new Swedish Prescribed Drug Register-opportunities for pharmacoepidemiological research and experience from the first six months. Pharmacoepidemiol Drug Saf 2007;16:726-35.

57 The Swedish prescribed drugs registry, 2020. Available: https:// www.socialstyrelsen.se/statistik-och-data/register/alla-register/ lakemedelsregistret/ [Accessed 9 Nov 2020].

58 ATC/DDD index 2016. Oslo, Norway., 2016. Available: http://www. whocc.no/ATC DDD INDEX [Accessed 11 Oct 2019].

59 The Swedish national patient register, 2020. Available: https:// www.socialstyrelsen.se/statistik-och-data/register/alla-register/ patientregistret/ [Accessed 9 Nov 2020].

60 Ludvigsson JF, Andersson E, Ekbom A, et al. External review and validation of the Swedish national inpatient register. BMC Public Health 2011:11:450.

61 Ljung R, Lundgren F, Appelquist M, et al. The Swedish dental health register - validation study of remaining and intact teeth. BMC Oral Health 2019;19:116.

62 The Swedish dental health registry (Tandhälsoregistret), 2020. Available: https://www.socialstyrelsen.se/statistik-och-data/register/ alla-register/tandhalsoregistret/ [Accessed 9 Nov 2020].

63 Ludvigsson JF, Svedberg P, Olén O, et al. The longitudinal integrated database for health insurance and labour market studies (LISA) and its use in medical research. Eur J Epidemiol 2019;34:423-37.

64 Ekström MP, Hermansson AB, Ström KE. Effects of cardiovascular drugs on mortality in severe chronic obstructive pulmonary disease. Am J Respir Crit Care Med 2013;187:715-20.

65 Ekström MP, Bornefalk-Hermansson A, Abernethy AP, et al. Safety of benzodiazepines and opioids in very severe respiratory disease: national prospective study. BMJ 2014;348:g445.

66 Short PM, Lipworth SIW, Elder DHJ, et al. Effect of beta blockers in treatment of chronic obstructive pulmonary disease: a retrospective cohort study. BMJ 2011;342:d2549.

67 Quint JK, Herrett E, Bhaskaran K, et al. Effect of $\beta$ blockers on mortality after myocardial infarction in adults with COPD: population based cohort study of UK electronic healthcare records. BMJ 2013;347:f6650.

68 Continuous or nocturnal oxygen therapy in hypoxemic chronic obstructive lung disease: a clinical trial. nocturnal oxygen therapy trial group. Ann Intern Med 1980;93:391-8.

69 Long term domiciliary oxygen therapy in chronic hypoxic cor pulmonale complicating chronic bronchitis and emphysema. Report of the medical Research Council Working Party. Lancet 1981;1:681-6.

70 Ekström M, Ahmadi Z, Larsson $\mathrm{H}$, et al. A nationwide structure for valid long-term oxygen therapy: 29-year prospective data in Sweden. Int J Chron Obstruct Pulmon Dis 2017;12:3159-69.

71 Palm A, Midgren B, Ljunggren M, et al. Socioeconomic factors and adherence to Continuous Positive Airway Pressure - a populationbased cohort study from the DISCOVERY cohort, 2020.

72 Ekström M, Albrecht D, Andersson SO. Validation of Swedevox registry of continuous positive airway pressure (CPAP), long-term mechanical ventilator (LTMV) and long-term oxygen therapy (LTOT). ERJ Open 2020;In press. 